\title{
The State of Innovation in Sweden and its Regions
}

\author{
Håkan Ylinenpää \\ Luleå University of Technology
}

\begin{abstract}
This article focuses on the successful Swedish tradition in the field of innovation, but also discusses the flip side of an innovation culture that honours only radical innovation. Related to this tradition is a preference to measure innovativeness through patent data. Both these traditions imply a disadvantageous position for regions and companies located outside our large metropolitan areas. One problem relates to the interest in understanding how different degrees of innovativeness relate to different degrees of economic and social effects - a challenge that patent data, only to a very limited degree, addresses. This means that patent data disregards the fact that also incremental innovations "new to the region" or "new to the firm" might be powerful routes to a more dynamic development path, especially in more peripheral regions. To overcome such shortcomings, other measures and approaches are needed. One such approach developed and presented in this article is based upon Data Envelopment Analysis (DEA) and the Malmquist productivity index-employing Swedish longitudinal data, the article illustrates how they may be utilized to assess and make sense of regional technological innovation. Besides offering an unconventional picture of the regional innovation performance in Sweden, this methodological approach also identifies the northernmost part of Sweden (the Norrbotten region) as a region with its own path-breaking development trajectory. The article is concluded by discussing the region of Norrbotten as an example of a region that has traditionally capitalized on the exploitation and processing of natural resources and how such a region may diversify into new sectors using concepts such as related variety and smart specialization.
\end{abstract}

The Northern Review 45 (2017): 57-75

Published by Yukon College, Whitehorse, Canada 


\section{Introduction}

Sweden has a long-standing track record of hosting an innovative economy. This is partly due to the fact that Sweden was not invaded during the Second World War and so instead could develop industrial innovations and large companies such as Alfa Laval (today it is still a world leader in heat transfer, centrifugal separation, and fluid handling); SKF (global manufacturer and supplier of ball and roller bearings, linear motion products, precision bearings, spindles, and seals); Sandvik (manufactures, for example, cemented-carbide and high-speed steel tools and blanks for the metalworking industry; equipment and tools for rock excavation, drills, and so on); Saab (serves the global market with world-leading products, services, and solutions from military defence to civil security); Scania (provider of sustainable transport solutions based on trucks and buses); and Volvo (manufactures cars, trucks, buses, construction equipment, marine and industrial power systems, and aerospace systems) - these are important drivers for a fast and steady growth of the Swedish economy during the hundred year period 18701970. After 1970, however, the Swedish economy faced several crises involving higher unemployment rates, a reduction and reconstruction of an oversized public sector, high taxes on labour and capital, and high inflation rates, with negative implications for stimulating entrepreneurship and innovation. A study in 2005 revealed, for example, that the fifty largest companies in Sweden were in fact all founded before 1970, and data from the Global Entrepreneurship Monitor (GEM) regularly positioned Sweden as a low-performing economy. From the mid-1990s onwards, however, due to structural reforms and government policy that are more directed toward supporting entrepreneurship and innovation, Sweden has managed to regain a more favourable position-for example, the level of innovation and the income per capita are higher than the mean for OECD economies (see Figure 1). In February 2013 The Economist described the recovery and vitalization of the Swedish economy as "a silent revolution" represented by a long series of reforms and liberalizations of the economy:

There can be no doubt that Sweden's quiet revolution has brought about a dramatic change in its economic performance. The two decades from 1970 were a period of decline: the country was demoted from being the world's fourth-richest in 1970 to $14^{\text {th }}$ richest in 1993, when the 
average Swede was poorer than the average Briton or Italian. The two decades from 1990 were a period of recovery: GDP growth between 1993 and 2010 averaged 2.7\% a year and productivity $2.1 \%$ a year, compared with $1.9 \%$ and $1 \%$ respectively for the main $15 \mathrm{EU}$ countries.

Institutional reforms and a reoriented policy stimulating entrepreneurship and innovation have been accompanied by new innovative companies entering the market. This largely includes service-based companies in the music, media, and tourism industries, for example. This could also imply that young people are considerably more interested in pursuing an entrepreneurial career compared to previous decades. Historical industrial successes, however, still influence Swedish priorities and preferences regarding the content and the value of different kinds of innovation, suggesting that Swedes normally cherish technical and radical innovations more than improved versions of something that already exists on the market. "New to the world innovations," such as those laying the foundation for so many large Swedish companies, are therefore praised and sought after more so than smart new concepts involving incremental innovation of existing products and services. "Copycats" relying on open innovation and improving something already existing are therefore far less respected than innovative industrialists relying on conventional patent rights and technical degrees of newness. Measuring patent statistics on a national, regional, and firm level is still a highly-used approach by influential politicians advocating a "re-industrialization" of the Swedish economy as a main development strategy.

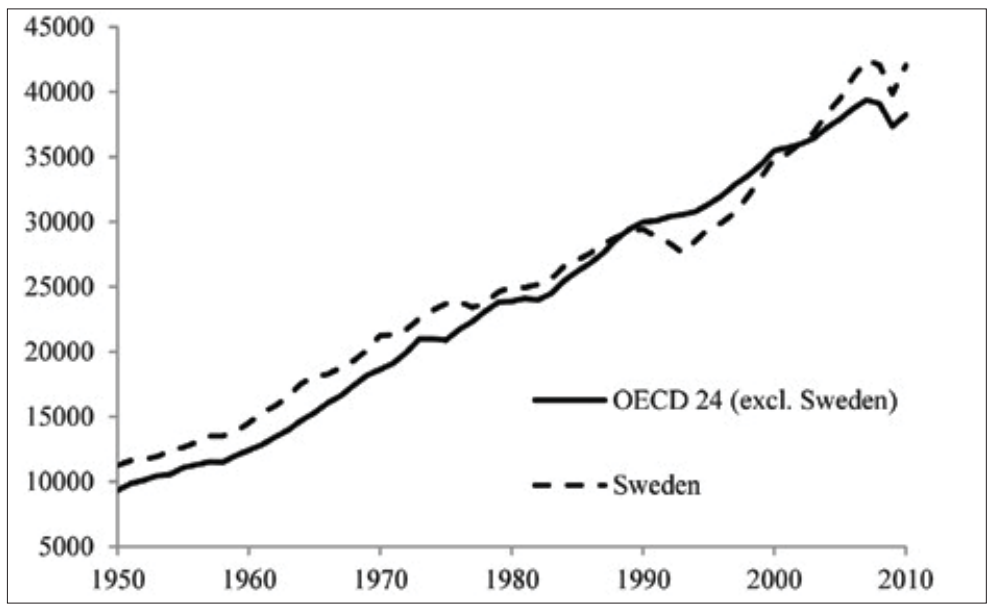

Figure 1. BNP per capita in OECD (excluding Sweden) and in Sweden 1950-2010, US dollars (Source: The Conference Board Total Economy Database, January 2012). 
This article elaborates on two main themes. The first theme is to discuss the fallacy of using patent data as the main indicator for regional innovativeness, and an alternative approach (Data Envelopment Analysis and the Malmquist productivity index) is presented and tested on Swedish regional data. Besides disclosing that peripheral regions such as Jämtland and Gotland, together with the capital region of Stockholm, come forward as leading innovative regions, this empirical test also identifies Sweden's northernmost region, Norrbotten, as a pattern-breaking region with a development trajectory very different from other Swedish areas. This article's second theme is to address this northern region's specific development conditions and its development strategy in order to explore regional smart specialization based on businesses and competence sectors that are related to but different from the region's historical competitive advantage.

\section{The Fallacy of Using Patents as an Indicator for Innovativeness}

Measuring immaterial property rights, such as patents, as indicators of innovativeness has a long-standing tradition in academic research. To measure innovativeness through patent data is, however, not unproblematic. One problem relates to understanding how different degrees of innovativeness relate to different degrees of economic and social effects - a challenge that patent data addresses only to a very limited degree since patents are granted to ideas normally classified as "radical innovations" and "new to the world." This means that patent data disregards the fact that incremental innovations that are "new to the region" or "new to the firm" might be powerful routes to a more dynamic development path. Another problem relates to the fact that patent data normally are registered at the corporate main office location, which often creates significant challenges for researchers trying to understand regional innovation patterns. For example, the old and established Swedish-owned multinational corporation Sandvik recently moved its main office from the small rural city of Sandviken in the northern half of Sweden to the World Trade Center building in Stockholm. As a result, the previously high rates of regional innovativeness for the Sandviken region were suddenly erased while the innovative scores for the Stockholm region (already hosting several companies' head offices) grew even higher. Despite these wellknown weaknesses, patent data continues to serve as a main innovation indicator, and thus also serves as a base for misguided policy implications.

Due to these shortcomings, there is an obvious need for new approaches for measuring innovation. One such approach, which 
distinguishes between using different types of innovation versus using patent data, is the Data Envelopment Analysis (DEA) and the Malmquist productivity index used by Anokhin and colleagues (Anokhin et al., 2011). DEA is a nonparametric programming technique that has been known in economics and operations literature for some time (Färe et al., 1994), but has only recently gained attention in the literature on innovation (Thursby and Thursby, 2002). Anokhin and colleagues conceptually develop and empirically illustrate the use of this technique for estimating regional technological innovation by using a Swedish longitudinal data set that contains information on all twenty-one Swedish counties over a five-year period from 2002 to 2006. In doing so, they demonstrate that the technique can be used to simultaneously explicate (1) regional technological expansions, (2) regional catching-up improvements in technologies, and (3) mere shifts in regionally used technologies.

The first kind of regional innovation is known as expansion and could be thought of as innovation in its grandest sense: introduction of more effective "new-to-the-world" resource combinations that are visibly superior to available alternatives. In other words, innovation of this kind surpasses known alternatives and expands the technological frontier within which all regions operate. It corresponds very closely to Schumpeter's "creative destruction" - a creative introduction of more effective new combinations that have the potential to destroy the foundation on which the competitive advantage of incumbents rests. Such expansions are most likely to be associated with innovation in its traditional, technical, narrow sense (e.g., patenting). Innovations of this kind require intense communication and collaboration between multiple parties such as firms, universities, research and innovation centres, and government agencies. Naturally, metropolitan regions are better positioned to provide access to these support resources as well as to the needed infrastructure for the innovating organizations. As such, the introduction of the "best" technologies is more likely to originate in such regions. Overall, prior research indicates that research and development (R\&D) activity, major product innovations, and patents tend to be concentrated in metropolitan regions (Feldman \& Audretch, 1999; Simmie, 2003). Metropolitan regions are known to lead this grand technological development as knowledge spillovers are often constrained to these centres (Audretsch \& Feldman, 1996; Baptista, 2003). Because metropolitan regions are magnets for talented individuals (Tödtling \& Trippl, 2005), the innovative advantage of such regions is further facilitated through a constant inflow of novel and complementary knowledge that supports the development of frontier 
technologies. Accordingly, Cooke and Morgan (1998) notice that metropolitan regions generally have better capacity to bring about fundamental leaps in technology and organizational practices. Peripheral regions, on the contrary, are considered to be less innovative, and tend to have fewer patents and R\&D investments, which leads to a focus on process and incremental innovations (Fritsch, 2000; Tödtling, 1992) that are less likely to be related to this kind of radical innovation.

The second kind of regional innovation has to do with lagging regions-those that are not at the technological frontier-trying to catch up with regions demonstrating exemplar innovativeness. The key is not the creation of new strategies and frameworks but rather recognitionand subsequent exploitation-of the more effective ways to combine resources by those entrepreneurially inclined. The exact fashion in which this is effectuated is less relevant from the regional perspective. Whether it is corporate entrepreneurs who recognize and adopt more effective technology introduced elsewhere, or new entrants who do the same thing and replace the regional incumbents who fail to respond to the creation of the more effective technologies, the end result is improved efficiency where resources are combined at the regional level. This kind of innovation is often explained in terms of knowledge spillovers from leading regions to lagging ones (Tödtling \& Trippl, 2005), where lagging regions innovate by mimicking or replicating know-how developed by leaders.

Although catching-up innovation may seem straightforward, in reality this is a rather complicated process because the flow of knowledge between regions is dependent upon interaction (Berglund \& Johansson, 2007; Cooke, 1998; Garofoli, 1994), and interaction may be restricted. To some extent, restrictions to effectively absorb new knowledge have to do with a poor supporting infrastructure and limited knowledge infrastructure in which the lagging regions' innovators are often embedded. Thus, the critical mass of key regional actors that has been shown to be extremely important for successful regional innovation (Cornett, 2009; Doloreux \& Dionne, 2008) is not reached. Accordingly, collective services are sub-par and may limit rather than facilitate technology transfer, thus hindering catch-up and perpetuating the lag. An even more significant threat for catching up can be found in the very mechanism of replicating the frontier technology and transferring the respective knowledge. Knowledge transfer is difficult without the transfer of people (Maskell \& Malmberg, 1999). Peripheral regions are often disadvantaged in terms of attracting highly skilled individuals qualified to effectuate technology transfer. Accordingly, such regions face a number of roadblocks to catching up with frontier regions, 
and run a high risk of constantly trailing behind (Feldman, 1994). In fact, it is likely that lagging regions located in close proximity to leading regions will have difficulty catching up since their best and brightest individuals prefer to seek employment in neighbouring leading regions. In some sense, being at a distance from magnets like capital regions may actually better prepare lagging regions to harness catching-up opportunities. Needless to say, this kind of regional innovation is very unlikely to be captured with traditional proxies for innovation such as patents, as it does not imply the creation of new commercially valuable knowledge but rather deals with the diffusion of already created (and perhaps patented) know-how.

A third kind of regional technological innovation focuses on shifts in a region's use of technology. Interestingly, regions' technological innovation trajectories are subject to conflicting forces. On the one hand, regions may exhibit a tendency for smaller and incremental changes because of path dependencies and regional competency traps. That such path dependencies apply in the context of innovation has been well documented (Tödtling \& Trippl, 2005). Regions are unlikely to seriously consider modifying the underlying technological basis due to the presence of lockin effects. Having developed expertise in a particular set of technologies, regions simultaneously have erected barriers to understanding alternative technologies. Accordingly, for decision makers, the mere possibility of shifting or changing their technology base is fraught with significant uncertainty. Thus, for a region that historically has relied on tourism and agriculture, switching to capital-intensive manufacturing is by no means a trivial exercise. Similarly, focusing on investments with uncertain returns can discourage organizations in lagging regional clusters to seek benefit from developing something new even though the current returns are disappointing. In addition, as Lawson and Lorentz (1999) argue, regions may develop skills indicating they are quite good in one line of business, and become trapped in their own competencies. This further limits their capacity to absorb new ideas from leading technologies. Innovation is also embedded in social relationships. Acknowledging that such relationships develop over time and are restricted due to culturally determined norms, routines, and values among regional actors may also restrict the development of substantially differing technologies (Johnson, 1992; Lorenzen, 1998).

As already indicated, the current state of the economic development literature does not present a single technique that could simultaneously capture the various aspects of regional innovations. Here, a DEA approach could be used to estimate the above-mentioned kinds of regional 
technological innovations. DEA could hence be used to estimate the extent to which regional innovations expand the historically best-known use of technology, how some regions catch up with the technological advancements of others, and how regional innovations have the potential to shift the use of current technologies in specific regions. This is the theme of the next section of this article.

\section{An Empirical Illustration Based on Swedish Regional Data}

The suggested approach to measuring regional technological innovation is illustrated based on a sample of Swedish regions over the course of five years (2002-2006). Administratively, Sweden is divided into twenty-one counties. As in most economies, however, these regions differ with respect to the structure and history of their industries and businesses, spanning the spectrum from expanding capital or metropolitan regions (such as the Stockholm region) to non-metropolitan regions with a tradition of industries such as agriculture and/or forestry (e.g., the counties of Gotland and Jämtland). While the first-mentioned type of regions are often characterized as national hubs for inward and outward relations for international or global industries and knowledge-based services, the development of the latter category is dependent to a high degree on industries exploiting unique but often small-scale technologies, a thriving tourism sector, and conventional services offered by public or private actors. A third category of regions is represented by counties such as Norrbotten, Västernorrland (both located in the northern part of Sweden), and Blekinge (in the southern part of the country), where a traditional industry based on natural resource exploitation during recent decades has been confronted with increasing global competition - a challenge that with varying degrees of success has been met by significant investments in efficiency improvement and capital rationalization.

Following the existing literature, we utilize physical assets (capital) and employment (labour) as regional resources combined to produce a gross regional product. This combination of resources is typical in many DEA studies (e.g., FÄRE et al., 1994), thus making the estimates comparable to those reported by other researchers.

Labour force indicators and gross regional product dynamics are both readily available statistics in Sweden and are accessed via the Regionfakta database. Physical assets (capital) estimates, in turn, are based on the dynamics of previously made capital investments, which is consistent with how the DEA literature approaches this issue (see, for example, Anokhin, Wincent \& Autio, 2011). While there is no single 
pre-specified rate of depreciation to be employed for estimating capital in DEA studies, most researchers employ rates ranging from 3\% to $15 \%$ (Kim \& Lee, 2004). Because Sweden makes substantial investments in capital and infrastructure and is located at the forefront of global development (OECD, 1997, 1999), a six-year equally paced depreciation period was adopted here, which is close to the recommended $15 \%$ rate. All investment data for Swedish counties throughout 1997-2006 were obtained from the Regionfakta database. To ensure data accuracy, the estimates were aggregated to the country level and correlated with the numbers reported for Swedish investments in fixed capital by the United Nations World Development Indicators database (which, unfortunately, only has information at the national, and not regional, levels). In all cases, highly significant, positive correlations reaching as high as $91.85 \%$ were obtained. The final sample thus consists of 105 observations of twenty-one counties over five years. The DEAP computer program (Coelli, 1996) was used to perform data envelopment analysis and Malmquist productivity index decomposition as recommended by Hollingsworth (2004).

The results demonstrate that Swedish regions do not invest equal amounts in research and development. Moreover, R\&D activities are very unevenly distributed across them. What we are witnessing, however, is that in spite of where a particular technology originated, most regions appear to align their use of resources with the dominant development trajectory. Certainly, they may pay a higher price for access to the new ways of resource organizing since innovators probably extract their rents from those wishing to benefit from their inventions. On the other hand, those regions that are typically viewed as "disadvantaged" do not have to incur the costs associated with producing the breakthrough or bear the ensuing uncertainty. Thus, they are seen as rather homogenous when looked at from the outside, and are analyzed as such. It is in this sense that the extant literature considers Sweden homogenous and finds it possible to compare it to other aggregate-level territorial units such as the State of Ohio in the United States (e.g., Braunerhjelm \& Carlsson, 1999).

As shown in Figure 2, three counties demonstrate substantially higher rates of technological change-Stockholm, Gotland, and Jämtlandwhich suggests that the reference technology for them differs from that which applies to most counties. While this was expected for Stockholm County - which is the major metropolitan county in Sweden - the results were somewhat unexpected for more peripheral and non-metropolitan regions such as Gotland and Jämtland. Interestingly, two of those counties (Stockholm and Jämtland) define the national frontier itself, and as 
such could not be measured with the same yardstick. Relevant national technology against which the majority of counties are assessed typically represents a weighted combination of the technologies employed by the leading innovators. Figure 2 depicts innovativeness of Swedish counties throughout 2002 to 2006. The figure suggests that regions bordering the leading Stockholm County often fail to pursue catching-up strategies, which is in line with the literature discussed earlier. As expected, there is no statistical relationship between this kind of innovation and more traditional proxies such as patenting.

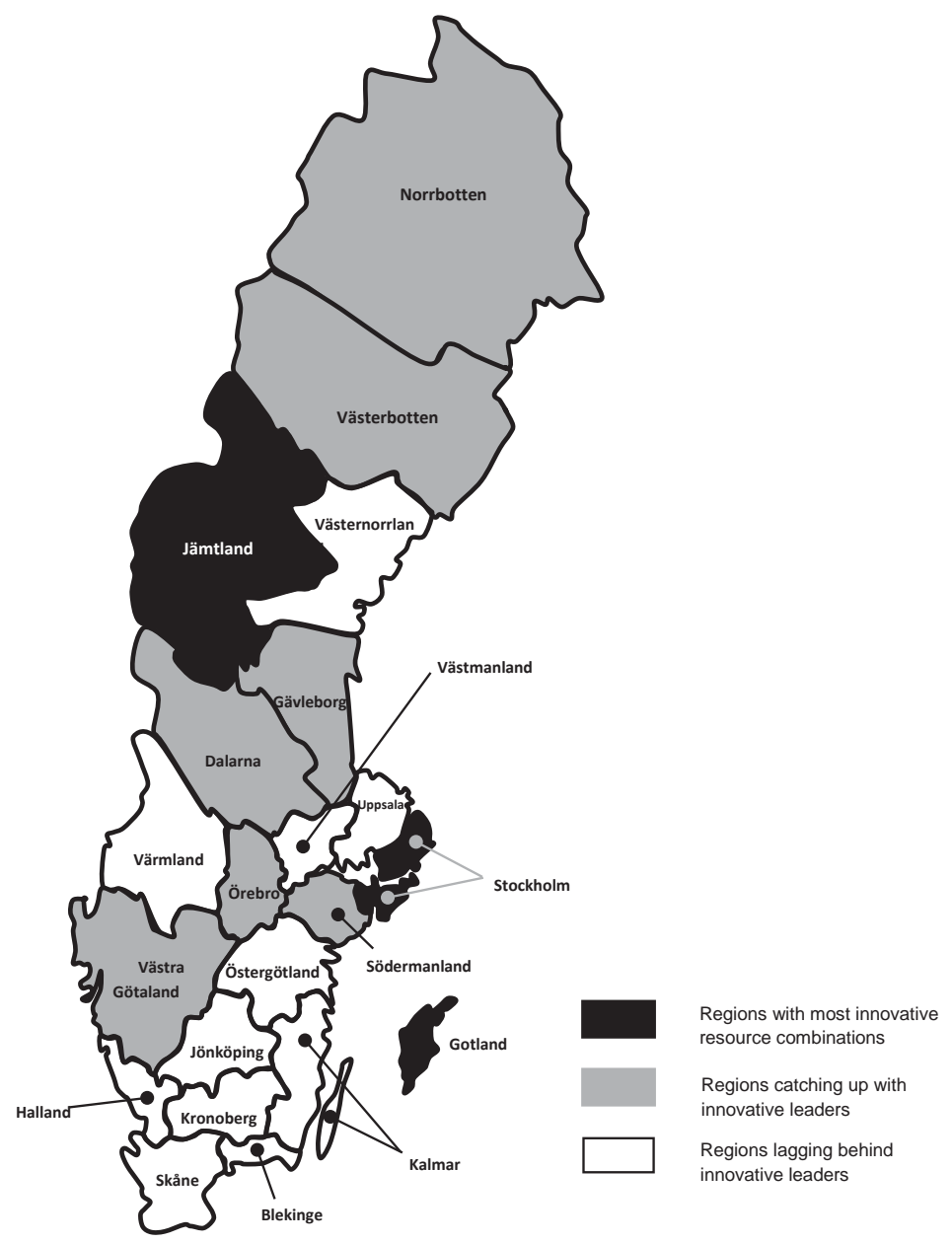

Figure 2. Innovativeness of Swedish counties, 2002-2006 
The results appear to have high face-validity in that they mirror the activities that have been going on in the Swedish economy. For example, the reason why non-metropolitan counties such as Jämtland and Gotland score high on innovativeness likely has to do with three specific regional characteristics. During the actual period of time under study (20022006), both regions made significant investments in the tourism sector, involving new or renovated hotel facilities, leisure cottages, and leisuretime activities, and infrastructure that helps these counties host more tourists, conferences, and other visitors to the regions. They have also been target counties for relocation of different government departments from the capital region (partly as a compensation for the reconstruction of the national military defence), which facilitated the inflow of highly qualified and connected individuals who are very important for regional innovation, as argued above. That is, the state (policy makers) started playing a significant role in innovative activities taking place within regions, above and beyond that which is attributable to purposeful or serendipitous actions of individual and corporate entrepreneurs. The regional institutions for higher education also expanded during this time. Gotland University was established in 1998 and is among the youngest and fastest growing university colleges in Sweden. The Mid Sweden University (with one campus in the county of Jämtland) has gradually developed during these years and received university status on 1 January 2005. Taken together, this has implied significant investments in both new physical premises and in highly skilled people, which has resulted in noticeably improved productivity in combining resources reflected in frontier expansions.

Figure 3 illustrates the expansion of the best national technology 2002-2006. In this figure, counties are plotted with respect to the amount of resources (labour and capital) they combine to produce 1 million Swedish krona (CAD \$155,300) worth of gross regional product. Generally, the closer to the origin (left bottom corner of the plot) the county is located, the more innovative it is. Counties developing their competitiveness through a smarter and more innovative combination of labour and capital over time, move towards the lower left of the figure (as marked with an arrow for the Stockholm region between 2002 and 2006). Counties far to the right and top (e.g., Blekinge County, which was suffering from restructuring of the region's industrial base in 2002) clearly demonstrate inferior performance with respect to regional innovativeness, but expose a development trajectory similar to the leading Swedish regions Stockholm and Jämtland. Those counties that are 
high on one dimension but low on another (such as Norrbotten County in 2006) are not necessarily problematic because they tend to substitute one resource with another (e.g., labour with capital), and as such are assessed against a respective section of the same frontier that is most favourable to them. From this perspective, the development of Norrbotten County between 2002 and 2006 illustrates the effect of substantial investments in the regional basic industries and communications infrastructure, implying cost reduction and less need for human labour-a rather innovative endeavour in its own right that would not necessarily be captured by traditional proxies for innovation such as patents or R\&D investments. In theory, a county that utilizes the least amount of a particular resource to produce a given amount of output could be deemed innovative and efficient even if it uses a disproportionate amount of another resource. DEA is equipped with tools to address such occurrences, as illustrated by the path-breaking pattern formed by the region of Norrbotten.

That the capital region of Sweden (Stockholm) captures a leading position in this kind of comparative analysis is not surprising. What is surprising is that the non-metropolitan regions, such as Jämtland, come forward in this study as regional front-runners. Reasonable explanations behind this have already been suggested, but may also relate to specific cultural factors outside the scope of this article. Jämtland (as well as the region of Gotland) may hence be characterized as counties where small and medium-sized companies traditionally have had an important role in the regional economy, fostering a more entrepreneurially oriented regional culture vis-à-vis such regions as Norrbotten and Blekinge where large companies traditionally have been cornerstones of the regional economy. As suggested by Martin and Sunley (2006), such path-dependencies contribute to fostering a more endogenous view of the world and the opportunities that it provides for innovation and development.

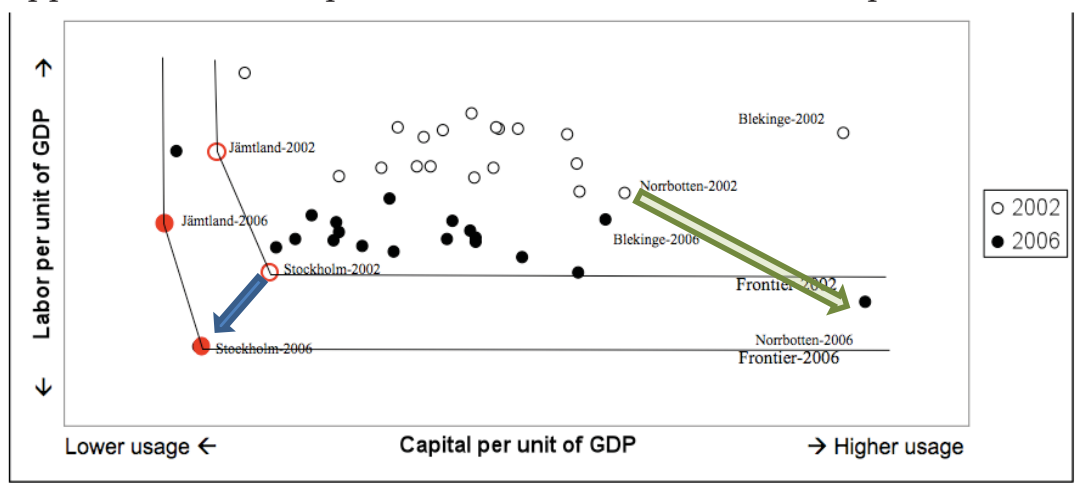

Figure 3: Shift of technological frontier in Sweden 2002-2006 


\section{The Norrbotten Region as an Empirical Illustration}

As already noted, and as shown in Figure 3, is the groundbreaking development trajectory of Norrbotten, the northernmost county of Sweden with around a quarter of a million inhabitants distributed on $25 \%$ of the Swedish landmass. The regional economy is traditionally based on extraction and refinement of natural resources such as iron ore and other minerals, electricity from the region's hydropower stations, and wood products - a result that, according to our findings, and depicted in Figure 3 above, seems to have been further underlined by the high levels of investments in basic industries and regional infrastructure.

From a historical perspective, the region of Norrbotten reveals obvious similarities with colonial economies in other parts of the world. Hundreds of years ago, the Swedish kingdom had a great interest in products like salmon, game, and tar. In order to facilitate the development of these natural resources (and to defend its property rights from competing interests such as the Russian tsar), the kingdom subsidized new settlers to move north. Development of minerals and wood products required more industrialized processes and a need for developed communications infrastructure. The Swedish railroad system was partly dependent on foreign (English) capital while the exploitation of different minerals relied to a high degree on the skills of Walloons from Belgium. Energy needed for industries in the southern part of Sweden became dependent on electricity generated from hydropower stations in the rivers of Northern Sweden. All this taken together implied a regional economy heavily dependent on cyclical fluctuations in market demand, causing periods of Klondikelike exploitation regularly replaced by recession, high unemployment, and the need for different kinds of support initiatives from the richer and more densely populated southern half of Sweden. According to a recent study (Ejdemo et al., 2016), the region's dependency on natural resource exploitation through mining, energy production, forestry, and a growing tourism sector is still a marked characteristic of the current regional economy, which imples a need to handle cyclical downturns in the regional economy.

One strategic investment made by the Swedish government to develop more resilience in the regional economy was the decision to establish higher education and research in Luleå in 1971. From the beginning, close collaboration with industry, business, and the community has been a hallmark of Luleå University of Technology, manifested, for example, by twenty-five centres for collaboration with the "outside world." The mission to co-operate in education and research is often denoted as the 
university's "third task," and during recent decades has been the top priority of most governments to develop further. The reason behind this is, of course, the benefits for developing a healthy, dynamic economy; indeed, a close interaction between "theory" and "practice" is expected to manifest in a more knowledge-based economy. In different evaluations of how this third task is performed, perceived, and used by industry, authorities, and government agencies (e.g., INNO, 1995; Ylinenpää, 2016), the university in Luleå comes forward as an academic institution with a high degree of professionalization and interest in external collaboration compared to other universities in Sweden. With an initial focus on the current basic industry in the region and its needs, the university has played an instrumental role in developing new industrial processes and products, and has contributed to a significant increase in the educational level of employees in the region. By diversifying into new areas such as computer science, business administration and social sciences, music and audio/film production, and so on, the role of the university as a seed bed for new companies and new knowledge areas in the region has increased. In this role as a source for new strategic knowledge, the university has been instrumental in the development of new forms of specialized regional competence in sectors such as the software and electronics industries, different forms of distance-spanning (remote) technologies, and media businesses.

\section{In Search of Models for Smart Specialization}

Classic economic theory suggests that in order to develop and maintain competitiveness regions should cultivate comparative advantages. In Europe, the European Union has coined the concept of "smart specialization" to denote how regions may (and should) develop their competitive advantages for the future, meaning specializing in one or a few strong regional industries or knowledge bases (cf. Foray et al., 2011; McCann \& Ortega-Argiles, 2011; Foray 2015). The smart specialization concept is, however, debated and sometimes questioned in the literaturefor example, the risk of lock-in effects preventing regions and companies from capturing new options for development (cf. Essletzbichler, 2007 or Bishop, 2009). Employing diversification rather than focus hence is often claimed to promote organizational and regional resilience and to counteract the risk of regional lock-in effects. Such arguments, however, normally generate the counter-argument that diversification is in fact a high-risk strategy involving the risk of becoming "stuck in the middle" 
without any real possibilities to develop any regional and/or companybased competitive advantage.

For more peripheral regions, the search for competitive advantage has often implied a specialization in natural resource exploitation early in the value chain, while more central regions (and especially capital regions) have taken the role of a coordination hub and a centre for a broad spectrum of head offices and an interface for trade of goods and services further on in the value chain. Specializing in specific forms of natural resource exploitation, however, often contains a high risk for lockin effects when cyclic demand and ongoing technical development may quickly change the rules of the game. This normally implies a regional economy characterized by hectic upturns and a booming economy that is regularly succeeded by depressing downturns and high unemployment rates.

Development and exploitation of a region's comparative advantage is hence a classic prescription for functional regional development. A regional competence in a specific field developed over time (and hence normally difficult to copy) is therefore a valuable regional asset as long as this competence is sought after by markets willing to pay the price to utilize its market offers. A changing market demand and/ or development of new technologies, however, constantly threatens this comparative advantage and challenges the region to develop new (but preferably related) offerings. This is often termed related variety, which denotes how regions and companies may develop new areas of expertise in fields related to, but different from, today's cash cows.

The traditional strategy to overcome lock-in related to the cyclical regional economy based on the exploitation of natural resources is to try and develop businesses further on in the value chain. The mining industry is therefore often complemented by iron works and the steel industry, and the forest industry by paper and pulp industries, sawmills, and other processing industries. These industries, while representing businesses closer to end customers in the value chain are, however, often affected by a similar fluctuation in market demand and business cycles. They accordingly do not represent sectors able to compensate for the roller coaster ups and downs in a regional economy dependent on natural resource exploitation.

A second often-used route towards a more balanced development trajectory in regions dependent on natural resources is to develop the tourism industry where natural assets such as rivers, mountains, beaches, wildlife, and wilderness are strategic resources. The development of a 
service-based industry also implies the introduction of a business sector very different from the often male-oriented culture characterizing many basic industries; thereby also contributing to a more attractive region. The mind shift from exploitation of natural resources through basic industries, to exploiting the wallets of wealthy visitors from other countries and regions, is not trivial, however. Conflicting interests between traditional industries in the region and the interests of an expanding tourism industry exploiting an unspoiled countryside are often an ongoing regional challenge.

In the region utilized as an illustrative case in this article (the Norrbotten region in the northern-most part of Sweden), the characteristics related to natural resource development and value-added manufacturing and secondary processing are also obvious and typical regional characteristics, supported by a university that more than forty years ago was established to support the basic industries in the region. The same goes for the region's ambition to develop tourism as "the region's new basic industry," manifested by large investments through regional authorities and European Union structural funds. This development strategy also corresponds well to the ambition to develop sectors that, in one way or another, are related to each other, rather than try to develop sectors without any apparent relation regarding regional competence, resources, or position in the value chain.

The Norbotten region recently experienced an unexpected link to a new and very different industry locating to the region. When the social media company Facebook chose Sweden and Luleå, after a thorough due diligence process in 2013, as the site for their first European data centre, this was regarded as a significant national and regional achievement. The national government (the Swedish Agency for Economic and Regional Growth together with the Ministry of Industry) conducted a study on the reasons why Facebook chose Lulea as the location site. As expected, reasons such as the cold climate, good communications facilities, and proximity to a well-respected technical university were important arguments in favour of Luleå. However, that access to suppliers able to deliver energy on time and at a reasonable cost were the most prominent arguments for locating in the northern part of Sweden (together with the fact that it is "green electricity" generated by hydropower stations in the region) was somewhat surprising. This regional competitiveness to deliver energy on time revealed another form of relatedness between two industries (the old established basic industry in the region and the new and "sexy" information and communications technology industry 
related to social media) that in public debate had often been regarded as antipodes. To discover that it was the regional competence to deliver renewable energy on time which turned out to be so decisive for Facebook was a true eye-opener in the public debate. This regional competence, fostered by decades of interaction with an industry exploiting natural resources where unplanned interruptions cost enormous amounts of money, in turn triggered a more nuanced discussion of what relatedness and related variety may involve in practice.

To conclude, this article contributes empirical data from Swedish regions in general, and from Sweden's northernmost region in particular, underpinning an analytical discussion on the prevailing challenges for non-metropolitan and peripheral regions to be competitive in the pursuit of developing into more innovative regions through smart specialization. One contribution is the employed DEA approach to disclose often neglected forms of regional innovation, thereby also offering policy makers and business managers a less biased picture of regional realities and challenges. Another contribution related to the case of Norrbotten is to broaden the understanding of what the concept of "related variety" (Boschma \& Gianelle, 2014) in fact may contain, disentangling from the analytical limitations set by concepts such as line of industry and business and value chains, and instead advocating the view that the content of regional and organizational competence is more decisive.

\section{Author}

Håkan Ylinenpää is professor of entrepreneurship and innovation, and research director of the Centre for Inter-organizational Innovation Research (CiiR) at Luleå University of Technology in Sweden.

\section{References}

Andersson, M. et al. (2013). The innovative Sweden. Sweden as a knowledge-based nation in an international context. Stockholm: Vinnova \& ESBRI (in Swedish).

Andersson, M. et al. (2015). The innovative Sweden 2. Innovation and attraction in cities and rural areas. Stockholm: Vinnova \& ESBRI (in Swedish).

Anokhin, S., Wincent, J., \& Autio, E. (2011). Operationalizing opportunities in entrepreneurship research: Use of data envelopment analysis. Small Business Economics, 37(1), 39-57.

Asheim, B.T., Boschma, R., \& Cooke, P. (2011). Constructing regional advantage: Platform policies based on related variety and differentiated knowledge bases. Regional Studies, 45(7), 893-904. https://doi.org/10.1080/00343404.2010.543126

Audretch, D.B., \& Feldman, M.P. (1996). R\&D spillovers and the geography of innovation and production. American Economic Review, 86(1), 630-640. 
Baptista, R. (2003). Productivity and density of regional clusters. In J. Bröcker, D. Dohse \& R. Soltwedel (Eds.), Innovation Clusters and Interregional Competition (pp.163-181). Berlin: Springer.

Berglund, K., \& Johansson, A. (2007). Entrepreneurship, discourses and conscientization in processes of regional development. Entrepreneurship $\mathcal{E}$ Regional Development, 19(6), 499-525.

Bishop, P. (2009). Spatial spillovers and employment growth in the service sector. The Service Industries Journal, 29(6), 791-803.

Boschma, R., \& Gianelle, C. (2014). Regional branching and smart specialisation policy. JRC Technical Reports, S3 Policy Briet Series No 06/2014.

Braunerhjelm, P., \& Carlsson, B. (1999). Industry clusters in Ohio and Sweden, 1975-1995. Small Business Economics, 12(4), 279-293.

Coelli, T. (1996). A guide to DEAP version 2.1: A data envelopment analysis (computer) program.

Cooke, P. (1998). Global clustering and regional innovation. Systemic integration in Wales. In H.-J. Braczyk, P. Cooke, \& M. Heidenreich (Eds.), Regional innovation systems (pp.245-262). London: UCL Press.

Cooke, P., \& Morgan, K. (1998). The associational economy: Firms, regions, and innovation. New York: Oxford University Press.

Cornett, A. (2009). Aims and strategies in regional innovation and growth policy: A Danish perspective. Entrepreneurship E Regional Development, 21(4), 399-420.

Doloreux, D., \& Dionne, S. (2008). Is regional innovation system development possible in peripheral regions? Some evidence from the case of La Pocatière, Canada. Entrepreneurship \& Regional Development, 20(3), 259-283.

Ejdemo, T., Söderholm, P., Ylinenpää, H., \& Örtqvist, D. (2016). Regional förnyelse av och i Norrbotten. En metaanalys av länets utvecklingsförutsättningar. Länsstyrelsen i Norrbotten, rapportserie 2/2016.

Essletzbichler, J. (2007). Diversity, stability and regional growth in the United States 1975-2002. In K. Frenken, (Ed.), Applied Evolutionary Economics and Economic Geography. Cheltenham: Edward Elgar.

Färe, R., Grosskopf, S., Norris, M., \& Zhang, Z. (1994). Productivity growth, technical progress, and efficiency change in industrialized countries. American Economic Review, 84, 66-83.

Feldman, M., \& Audretch, D. (1999). Innovation in cities: Science-based diversity, specialization and localized competition. European Economic Review, 43, 409-429.

Feldman, M.P. (1994). The geography of innovation. Boston: Kluwer Academic Publishers.

Foray, D. (2015). Smart specialisation-Opportunities and challenges for regional innovation policy, regions and cities. London: Routledge.

Foray, D., David, P.A., \& Hall, B.H. (2011). Smart specialisation. From academic idea to political instrument, the surprising career of a concept and the difficulties 
involved in its implementation. Lausanne: Management of Technology \& Entrepreneurship Institute (MTEI) working paper, November 2011.

Fritsch, M. (2000). Interregional differences in R\&D activities-An empirical investigation. European Planning Studies, 8, 409-427.

Garofoli, G. (1994). The industrial district of Lecco: Innovation and transformation processes. Entrepreneurship \& Regional Development, 6, 371-393.

Högfeldt, P. (2005). The history and politics of corporate ownership in Sweden. In R.K. Morck. (Ed.), A history of corporate governance around the world: Family business groups to professional managers (pp. 517-580). Chicago and London: University of Chicago Press.

Hollingsworth, B. (2004). Non parametric efficiency measurement. The Economic Journal, 114, 307-311.

Johnson, B. (1992). Institutional learning. In B.-Å Lundvall (Ed.), National innovation systems: Towards a theory of innovation and interactive learning. London: Pinter Publishers.

Kim, J.W., \& Lee, H.K. (2004). Embodied and disembodied international spillovers of R\&D in OECD manufacturing industries. Technovation, 24, 359-368.

Lawson, C., \& Lorenz, E. (1999). Collective learning, tacit knowledge and regional innovative capacity. Regional Studies, 33(4), 305-317.

Lorenzen, M. (1998). Specialization and localized learning: Six studies on the European furniture industry. Copenhagen: CBS Press.

Martin, R., \& Sunley, P. (2006). Path dependence and regional economic evolution. Journal of Economic Geography, 6, 395-437.

Maskell, P., \& Malmberg, A. (1999). Localised learning and industrial competitiveness. Cambridge Journal of Economics, 23, 167-185.

McCann, P., \& Ortega-Argilés, R. (2011). Smart specialisation, regional growth and application to EU cohesion policy. Economic Geography Working Paper 2001, Faculty of Spatial Science, University of Groningen.

OECD. (1997). National innovation systems. Paris: OECD.

OECD. (1999). Managing national innovation systems. Paris: OECD.

Simmie, J. (2003). Innovative cities. London: Spoon.

Thursby, J.G., \& Thursby, M.C. (2002). Who is selling the ivory tower? Sources of growth in university licensing. Management Science, 48, 90-104.

Tödtling F., \& Trippl, M. (2005). One size fits all? Towards a differentiated regional innovation policy approach. Research Policy, 1203-1219.

Tödtling, F. (1992). Technological change at the regional level: The role of location, firm structure, and strategy. Environment and Planning, 24, 1565-1584.

Ylinenpää, H. (2016). Kan universitet och högskolor vara både höger- och vänsterhänta? Några reflektioner utifrån fallet Luleå tekniska universitet. In M. McKelvey \& O. Zaring (Eds.), Sveriges entreprenöriella ekosystem. Stockholm: ESBRI. 